\title{
A numerical simulation of underwater slope failures generated by salt diapirism combined with active sedimentation
}

\author{
N. KOVACEVIC*, R. J. JARDINE $\dagger$, D. M. POTTS $\dagger$, C. E. CLUKEY $\$$, J. R. BRAND§ and D. R. SPIKULA**
}

This paper describes advanced finite-element simulations of a geologically active and periodically unstable $700 \mathrm{~m}$ high underwater escarpment located in the Gulf of Mexico that has been created by uplifting salt diapirs combined with sediment deposition. The site's geological history, soil permeability and clay shear strength characteristics govern current slope stability, and determine the timing of any future failure. The geological and geotechnical conditions are reported before presenting fully coupled, large-displacement numerical simulations employing critical state formulations of the slope's evolution over the last 600000 years. The latter form the basis for strain-softening analyses of the pore pressure equalisation and progressive failure processes that control current slope stability. The analyses also address the ground movement patterns that precede instability, giving useful information for geohazard risk assessment and early warning monitoring system design.

KEYWORDS: failure; landslides; numerical modelling; offshore engineering; slopes
La présente communication décrit des simulations aux éléments finis d'un escarpement sous-marin géologiquement actif et périodiquement instable de $700 \mathrm{~m}$ de haut, situé dans le Golfe du Mexique, créé par le soulèvement de diapirs salés allié à des dépôts de sédiments. L'histoire géologique du site, la perméabilité du sol et la résistance au cisaillement de l'argile déterminent la stabilité actuelle de la pente, ainsi que le moment de la survenance de glissements futurs. Les conditions géologiques et géotechniques sont communiquées avant la présentation de simulations numériques à déplacement significatif entièrement couplées, en faisant usage de formules à état critique de l'évolution de la pente au cours des 600000 dernières années ; ces dernières constituent la base d'analyses de réduction de la résistance à la déformation de l'égalisation de la pression interstitielle et de processus de glissements progressifs déterminant la stabilité actuelle de la pente. Les analyses se penchent également sur les tendances des mouvements du sol précédant l'instabilité, en fournissant des informations utiles sur l'évaluation des risques de dangers géologiques et la conception d'un système de contrôle d'alerte rapide.

\section{INTRODUCTION}

Deepwater hydrocarbon exploration is taking place worldwide in geologically young and active provinces. The Sigsbee escarpment in the Gulf of Mexico presents one example where long escarpments have been created by locally uplifting salt diapirs accompanied by large-scale sediment deposition. Nowacki et al. (2003), Orange et al. (2003) and Young et al. (2003), among others, describe the interplay between geology, tectonics and large underwater slope failures in this region. These features are critical to assessments of potential present-day geohazards.

This paper describes an advanced finite-element (FE) study of an approximately $700 \mathrm{~m}$ high Gulf of Mexico escarpment. The approach builds from a 'first principles' analysis of the slope's occasionally unstable evolution over the last 600000 years to give predictions for the pore pressure equalisation and progressive failure processes that govern current and future slope stability. The latter captured brittle strain-softening within the plastic clay strata. It is shown that, along with geological history and unit weights, the clay's permeability and post-peak shear strength characteristics control stability, and determine the timing of any future failure. The analyses also consider ground movement

Manuscript received 28 October 2011; revised manuscript accepted 1 May 2012.

Discussion on this paper closes on 1 February 2013, for further details see p. ii.

* Geotechnical Consulting Group, London, UK.

$\dagger$ Imperial College, London, UK.

\pm BP America, Houston, TX, USA.

$\S$ Intecsea, Houston, TX, USA.

** Forum Energy Technologies, Houston, TX, USA. patterns, giving useful information for geohazard assessment and early warning monitoring system design.

\section{FE ANALYSES OF PROGRESSIVE SLOPE FAILURE}

Submarine slope stability is routinely examined by offshore engineers using limit equilibrium methods (e.g. Poulos, 1988). A fundamental limitation of such approaches is their inability to capture the progressive failure processes that are known to develop in sensitive clays (Nowacki et al., 2003; Kvalstad et al., 2005), and in brittle soils whose shear strengths can degrade from peak to residual values as a result of clay particle reorientation (Skempton, 1977). The authors' approach is rooted in Potts et al.'s (1997) treatment of delayed failures in cuts formed in stiff plastic overconsolidated clays, which have been widely reported in highway and railway engineering (Parsons \& Perry, 1985). This paper describes one example where the approach has been incorporated into large-scale offshore geohazard assessment studies. Another example was a contribution to the Ormen Lange site and Storegga slide studies (Kvalstad et al., 2005).

Delayed failure is triggered by: (a) pore pressures being initially depressed after relatively 'quick' and almost 'undrained' slope excavation; and (b) subsequent hydraulic equalisation, coupled with progressive post-peak strain-softening towards residual shear strength (Skempton, 1977). Similar arguments apply to natural landslides, where large run-outs or mass wastage by erosion remove the slip mass rapidly (Hutchinson, 1973). The slides often follow geological histories that leave relic systems of faults, fissures and occasionally large, tectonically induced shears (Chandler et al., 1998). Orange et al. (2003) describe how tectonic conditions along the Sigsbee escarpment generated discontinuities and slides. Existing discontinuities can impact on slope stability when 
their orientations reinforce, or even override, progressive failure mechanisms that might otherwise develop within the soil mass (Kovacevic et al., 2007).

Potts et al.'s (1997) analyses concentrate on cases where pre-existing discontinuities do not dominate, although the effects of fissures can be addressed when assigning operational shear strength parameters. They emphasise the importance of capturing the key geological and geotechnical processes if continuum analyses are to predict the growth of reduced-strength shear zones that eventually govern slope stability. They have been able to predict a broad sweep of observed 'first-time' collapse mechanisms and failure times successfully, which cannot be achieved through routine limit equilibrium slope stability analysis. Failure modes and times are controlled by

(a) the initial internal stress regimes

(b) the clay brittleness and low-strength residual shear surfaces

(c) the non-linear permeability characteristics

(d) the boundary conditions.

The internal stress regime of originally flat ground can be described by specifying $K_{0}$ values or profiles, but this simple approach cannot be applied to the far more complex internal stress regime induced by salt diapirism, differential sediment deposition and slope processes at the Gulf of Mexico study area. Recognising that the stress regime is one of the most important factors in progressive slope failure, the first part of the present study focused on simulating the internal stresses that result from the site's geological history.

Development work was necessary with the FE code ICFEP (Potts \& Zdravkovic, 1999), to allow deposition and slope excavation under deep water. Whereas Potts \& Zdravkovic (2000) dealt with the problem of excavation, construction under water turned out to be even more complex. Fig. 1 shows schematically the various issues involved. At the beginning of the analysis, the initial effective stresses and pore pressures in the soil are in equilibrium with the external (sea-level) water pressures (Fig. 1(a)). Construction then involves several simultaneous processes. The external water pressures between points $\mathrm{A}$ and $\mathrm{B}$ are removed (Fig. 1(b)). Construction of a row of elements is performed (Fig. 1(c)) by applying self-weight body forces, and specifying the internal pore pressures equivalent to the adopted sea level. To maintain the equilibrium, nodal forces matching the external water pressures have to be applied to the 'newly' formed soil surface, and pore water pressure boundary conditions must be applied to the consolidating nodes at the boundary (Fig. 1(d)). All of the above activities, as depicted in Figs 1(b)-1(d), are performed in the same increment, and consequently complex bookkeeping algorithms are required to keep track of the various forces involved. The issues related to excavation and construction under water are further complicated by the need to employ a large-displacement, fully coupled formulation herewith to account for the geologically active conditions. In such a formulation, the

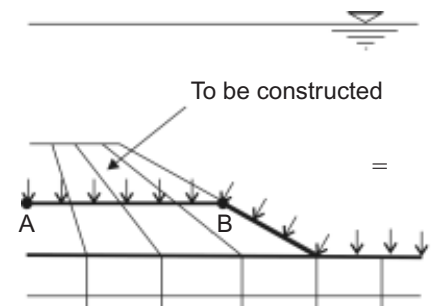

(a)

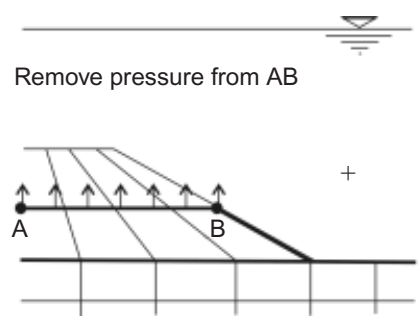

(b) mesh boundaries move and change shape. Consequently, it is essential to continuously update the boundary conditions during 'incremental' calculations. The boundary stresses and pore pressures (both internal and external) are conveniently defined with respect to the fixed sea level. High precision is required in cases where water pressures are large but effective stresses are low. In addition, the equivalent nodal forces resulting from the applied boundary stresses are dependent on the changing shape of the element boundaries.

\section{GEOLOGICAL SETTING, STRUCTURE AND}

EVOLUTION OF THE ESCARPMENT STUDY AREA

Multiple regional and local geophysical studies have investigated the geological setting, structure and evolution of the escarpment area applying hydrocarbon exploration threedimensional (3D), high-resolution 3D, multibeam echosounder and chirp sub-bottom profiler systems. These surveys presented the first indicators of progressive slope failure. The main geological processes over the last 1 million years were interpreted as

(a) substantial basal uplift driven by salt movement and diapirism

(b) distortion and faulting of the older strata overlying the diapir

(c) relatively rapid deposition of several hundred metres of predominantly clay sediments above and behind the diapir, with thicknesses that vary strongly spatially as a result of diapirism

(d) distortion and faulting in the recent sediments

(e) large-scale failures of the escarpment slope that either ran out, or were eroded away relatively rapidly.

The general ground model is illustrated in Figs 2 and 3. The escarpment is underlain by the thin leading edge of a shallow salt body that extends several kilometres seaward of its deeper salt-feeder system. Salt movement is thought to have originated as a horizontal/subhorizontal sheet that generated a compression zone ahead of the salt front, which manifests as a large thrust that apparently originates from the base of the salt. The basal movements have evolved towards a differential vertical uplift pattern that produces a broad, shallow anticline in the overlying sediments, and a high-amplitude fold directly above the salt.

The geophysical sections indicate that the overlying sediment section initially responded in the clay slab 'bent-beam' style discussed by Cloos (1968). Single and conjugate extensional faults formed, with peak extension starting on the outer surface and propagating into the 'beam' as extension and deformation progressed (see Fig. 2). Multiple normal faults are interpreted as developing throughout the 'bentbeam' stratigraphic section to accommodate the continuing deformation imposed by the uplift. The hinge-of-the-fold (peak extension) location faults are the most important, and propagate deepest into the section. The amplitude of the fold increased as the structure evolved, with new discontinuities

Fig. 1. Processes involved in modelling construction under water

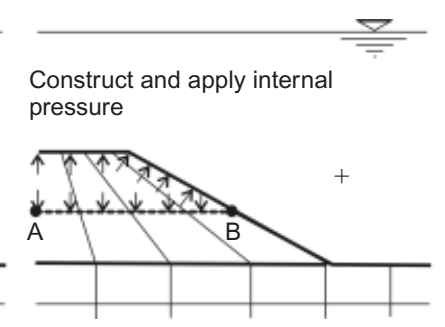

(c)

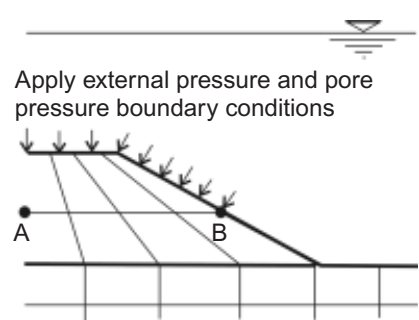

(d) 


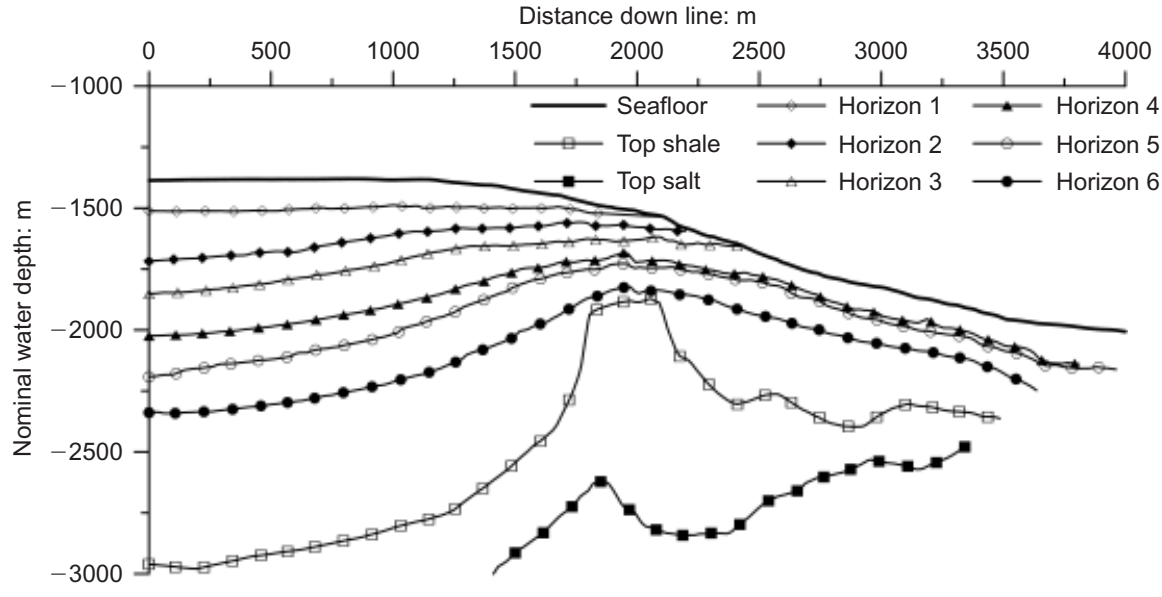

Fig. 2. Stratigraphy established from geophysical profile run along slope

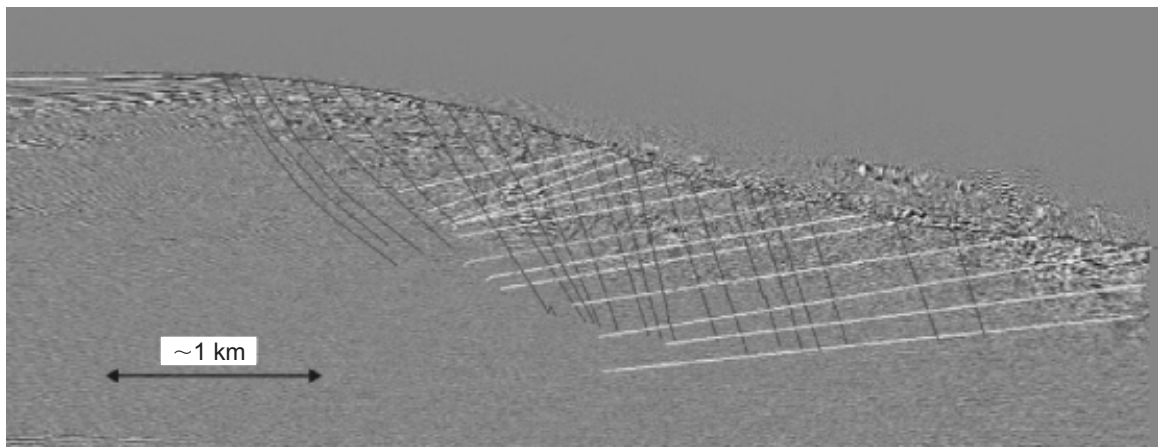

Fig. 3. High-resolution 3D seismic line illustrating geometry of faulting in the scarp. Dark lines represent first-generation family evolved during 'bent-beam' response to uplift. White lines represent second-generation formed at orientations that accommodated the rotation and steepening at the seaward forelimb

forming at orientations that accommodated the rotation and steepening of the seaward forelimb of the fold, at the formal scarp. High-resolution 3D seismic techniques were critical in identifying these features and discontinuity sets that indicated a susceptibility to brittle shear failure. The normal faults and the shear surfaces that form progressively at the forelimb of the scarp are interpreted as contributing to periodic cycles of gravity sliding.

Sedimentation continued at a relatively rapid rate over the period of uplift. Detailed analysis of the regional geophysical information established, at locations landward of the uplifting salt edge, a thick (up to $1 \mathrm{~km}$ ) sequence of nearcontinuous, almost horizontal sediments overlying the salt. Closer to the scarp edge, the thicknesses of each sedimentary layer were modified by the uplifting salt and the distortion of the overlying existing sediments. This is outlined in Fig. 2 by an orthogonal section produced from quantitative analysis of the geophysical data. The section shows the current seabed profile, and picks out six reflective marker horizons (H1 to H6). A shallow Holocene layer is also present, but cannot be seen at this scale. Its base defines an $\mathrm{H} 0$ horizon.

Intrusive site-specific investigations included shallow borings and seabed probing. Review of the regional geophysical datasets allowed horizons $\mathrm{H} 0$ to $\mathrm{H} 6$ to be traced back to deep geotechnical borehole locations at nearby hydrocarbon development sites. They provided substantial geotechnical and sediment dating datasets (as reported for other Sigsbee sites by Young et al., 2003) that aided ground model development and guided geotechnical parameter selection. High-quality samples proved predominantly clay strata, while the seismic stratigraphy implies a sequence of continuous, but alternating, sediment units of varying thickness. The deep borehole data revealed clays of varying compositions, with about one third classifying as having liquid limits (LL) greater than $60 \%$, which were considered as showing 'high plasticity'. Isolated (marginally permeable) sand or intercalated sand-clay units were identified at other locations on the escarpment slope.

One potentially vital aspect of the sediments' behaviour was the degree to which they might form low-strength residual shear surfaces when strained beyond peak. Borehole sample descriptions noted the presence of slickensided shear surfaces in some high-plasticity clay samples; the latter are indicative of a propensity to form low-strength residual shear surfaces. A programme of six ring-shear tests was performed at Imperial College on selected medium- to high-plasticity deep-boring samples. As discussed later, the samples with LL close to or greater than $60 \%$ formed very low-strength residual shear surfaces, a feature that impacts considerably on slope stability. The interpretation made for the FE analyses is that the strata were deposited as alternating sequences of continuous layers of alternating plasticity.

\section{APPROACH TO QUANTITATIVE ANALYSIS OF ESCARPMENT EVOLUTION}

The simplified modelling of the last 600000 year history of the escarpment and sedimentary basin involved a 'bottom-up' geological and geotechnical procedure. This allowed uplift, deposition and prior sliding to define the stress regime within the present slope, and set the conditions for subse- 


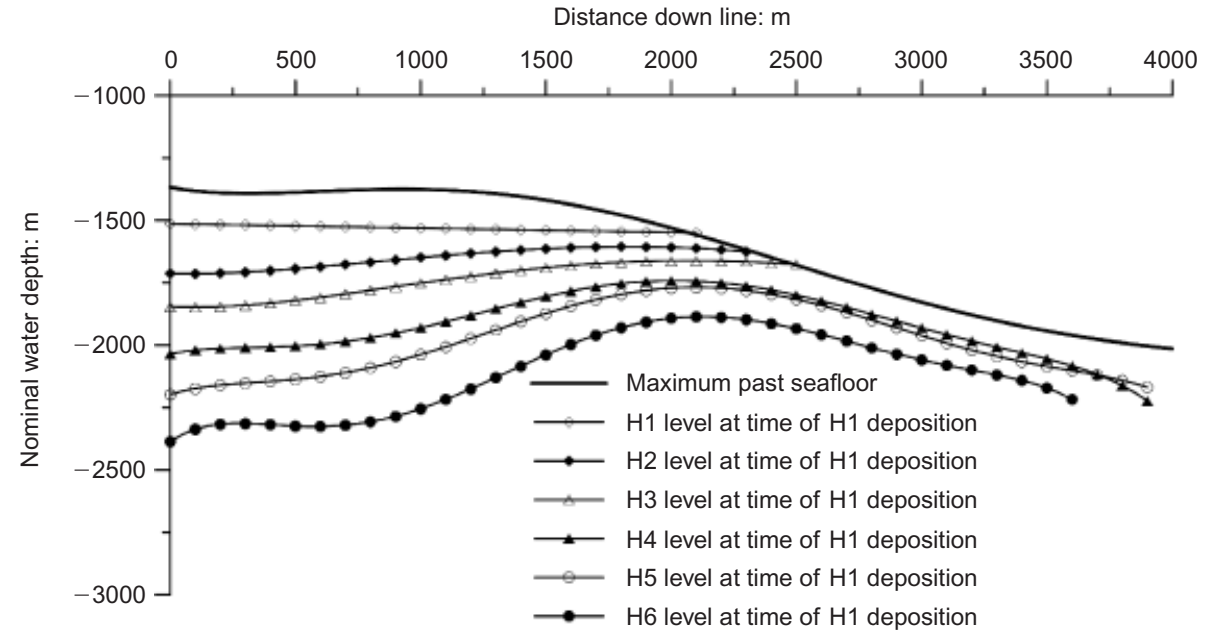

Fig. 4. First reconstructed profile: Horizon 1 depositional setting

quent progressive failure analyses. It was recognised that it would be difficult to incorporate multiple prior cycles of sliding at the escarpment site. Noting that the ultimate goal was to set the conditions for analyses of progressive failure mechanisms that might be propagating during present times, emphasis was placed on developing a realistic description of the internal stress conditions acting prior to the last slope failure, without encouraging any earlier instability. Applying the literature reviewed by Poulos (1988) shows that the surface waves are unlikely to be influential at this deepwater location. It was also decided to neglect any possible earlier seismic events in reconstructing a simplified site stress history.

The first step was to interpret the geophysical information shown in Fig. 3 to establish the quantitative relationships along each reflective horizon between (a) the lateral position, (b) the salt uplift, (c) the horizon elevation and (d) the thickness of each main sedimentary unit. This is illustrated in Fig. 4, considering the conditions thought to apply when Horizon 1 was deposited. The ages of the marker horizons were estimated from sample dating, providing layer shapes

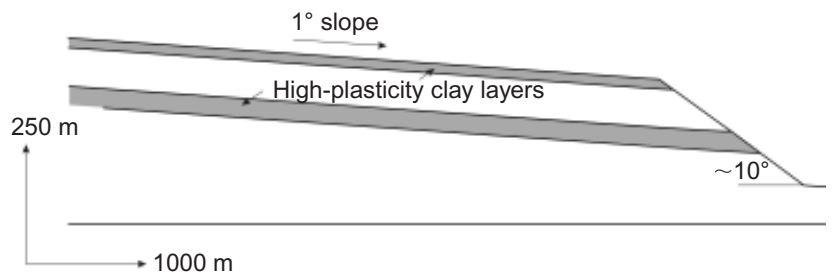

Fig. 5. Layering system assumed at time of Horizon 3 deposition. Modelled sedimentation rate between Horizons 4 and 3 corresponds to $7.4 \mathrm{~mm} /$ year. Note vertical exaggeration of scale

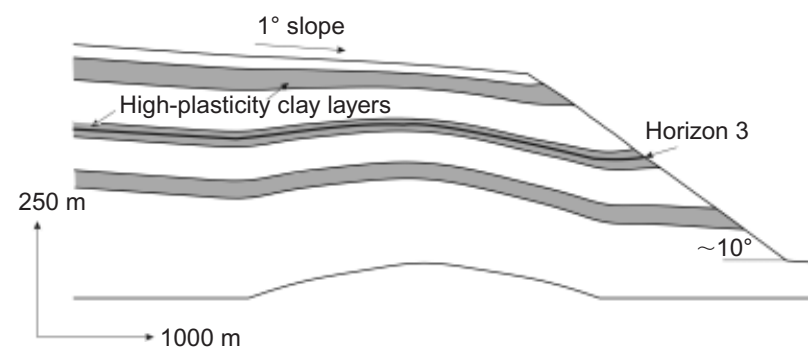

Fig. 6. Layering system assumed at time of Horizon 2 deposition. Modelled sedimentation rate between Horizons 3 and 2 corresponds to $3.2 \mathrm{~mm} / \mathrm{year}$. Note vertical exaggeration of scale and deposition rates that formed both inputs and targets for the FE simulations.

The main sequences modelled of sediment deposition, basal uplift, sediment distortion and finally major landsliding are illustrated in Figs 5 to 8. The patterns of deposition and distortion imposed were based on quantitative interpretation of the geophysics. The clays were built up as initially subhorizontal layers of marine sediment (up to $700 \mathrm{~m}$ thick)

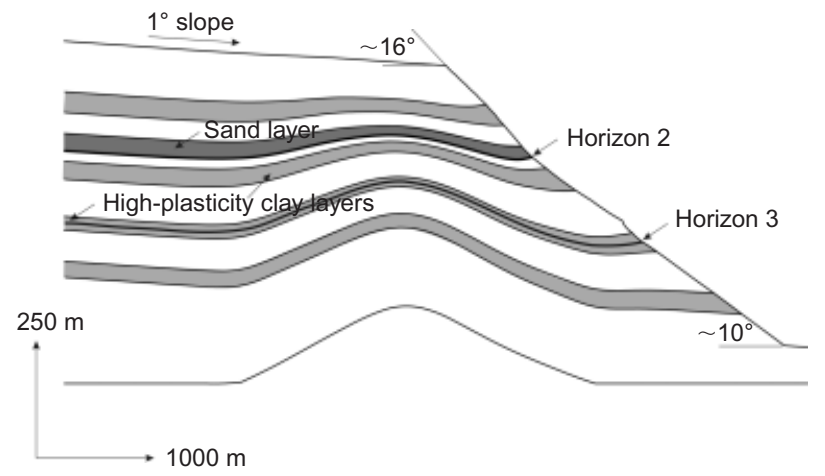

Fig. 7. Layering system assumed at time of Horizon 1 deposition. Modelled sedimentation rate between Horizons 2 and 1 corresponds to $0.8 \mathrm{~mm} /$ year. Note vertical exaggeration of scale

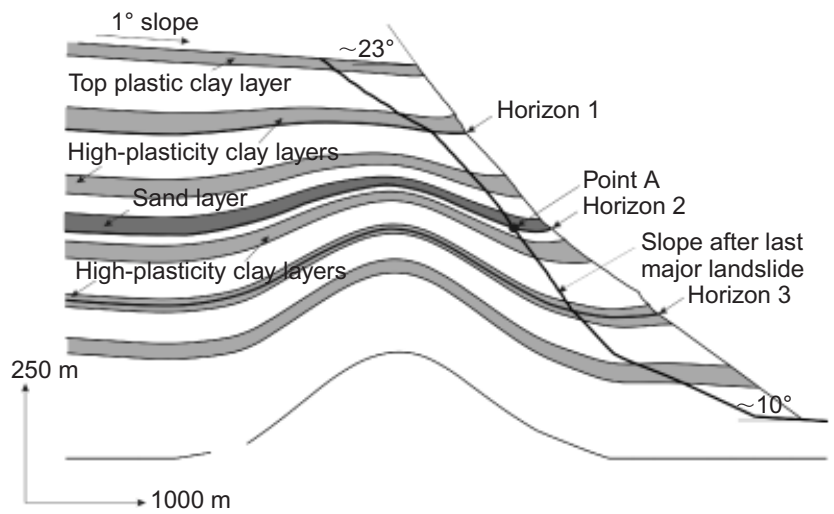

Fig. 8. Layering system assumed at time of Horizon 0 deposition. Modelled sedimentation rate between Horizons 1 and 0 corresponds to $0.5 \mathrm{~mm} / \mathrm{year}$. Note: point $A$ and assumed basal profile of last major landslide that occurred c. $5000 \mathrm{BP}$; all landslide material is assumed to have run-out; and vertical exaggeration of scale 
that settled gradually under self-weight, while being simultaneously distorted by uplift (up to $236 \mathrm{~m}$ ) imposed from below. These processes imposed shear and volume strains exceeding $50 \%$ at some locations, and led to a final slope profile that matched (a) the distorted geophysical stratigraphy and (b) the maximum past seafloor shape interpreted from the regional geomorphology. Comparison with the flatter, present slope profile indicates the mass lost by prior slumping and/or erosion. The latter processes left much of the deposits under the sloping section in an 'overconsolidated' state, as verified by borings and probing tests. Sample dating (which involves scatter of up to $15 \%$ ) and geomorphological interpretation suggest that the last major masswasting occurred 5000 to 8000 BP.

The horizontal base of the FE mesh was selected to coincide with Horizon 4, which was assumed to have been deposited c. 600000 BP. Fig. 5 illustrates the succession assumed for the stage (c. $450000 \mathrm{BP}$ ) when Horizon 3 was being deposited with a very gentle dip $\left(1^{\circ}\right)$ and a frontal slope of $10^{\circ}$ that matches the interpreted maximum past seafloor shape. FE mesh considerations made it convenient to distribute the high-plasticity layers to make up one third of the profile by positioning one midway between Horizons 4 and 3, and to assume that Horizon 3 itself was in the middle of the second plastic layer; Figs 6 to 8 show the layering sequences found most convenient for subsequent stages, including the 'sand' layer assumed to exist above Horizon 2 in one check run. The seismic records indicate that local salt uplift was relatively minor between Horizons 3 and 4, leaving the simple system shown in Fig. 5. Uplift is thought to have become more important during the next cycle of sedimentation, and the progressive interaction between deposition, uplift and strata distortion is illustrated in Figs 6 to 8. Diapir uplift was applied by imposing a parabolic upward displacement boundary condition over the base of the FE mesh (i.e. over Horizon 4) to impose a maximum of $236 \mathrm{~m}$ of uplift on the strata above Horizon 4. The fully coupled analyses showed high degrees of drainage under the simulated uplift and deposition rates over the 600000 -year period considered. The highest excess pore pressures developed at the undrained base, and amounted to less than $10 \%$ of the nominal effective overburden pressure.

In this approach, most of the sediment remained geologically normally consolidated up to just before the last 'main landslide' (5000 to $8000 \mathrm{BP}$ ), which occurred when the seafloor profile had built up to its steepest-ever inclination. Recalling the aim of avoiding slope failures before this stage, critical-state soil models that did not capture possible residual fabric formation were employed up to this point. It is possible that incorporating brittleness from earlier stages could have produced instability and 'overconsolidation' by mass wasting involving earlier slides on gentler slopes. However, modelling these events would have made the analysis considerably more complex, and would have led less directly to the desired outcome: a realistic set of initial conditions for the present-day progressive failure analyses.

\section{APPROACH FOR PROGRESSIVE FAILURE ANALYSES OF HOLOCENE SLOPE STABILITY}

After simulating the escarpment's evolution over the last 600000 years, the FE analyses considered the response following a single mass-wasting landslide event c. 50008000 BP. The slide was simulated as an excavation stage that cut into the predicted 'maximum past' profile to leave the present slope (see Fig. 8). The debris was assumed to have either run out fully or been eroded away rapidly. The following period of hydraulic equalisation was governed by the soils' compressibility and permeability laws, with flow (a) into the 'newly overconsolidated' areas, where the simulated landslide reduced total stresses and depressed pore pressures, and (b) out of any zones with excess pressures.

The analyses run after the excavation was complete employed a different soil model for the plastic clay layers. The latter were allowed to strain-soften post-peak towards the lower-bound residual strengths indicated by ring-shear tests. Any failure mechanisms that developed were identified. Checks were made on the margins of stability at different stages of the strain-softening analyses by raising soil unit weights incrementally in separate runs until collapses occurred. 'Non-softening' runs were also performed as control cases. The presence of the sand layer and the role of dilatancy in the medium-plasticity clay layers were also examined, aiding the overall interpretation, as shown later.

\section{SOIL MODELS AND PARAMETERS}

A variant of the modified Cam-clay model (Roscoe \& Burland, 1968) was selected to represent the clay layers over the main part of the escarpment's geological history. Given that such models can significantly overestimate failure stresses on the supercritical ('dry') side (Gens \& Potts, 1988), a Hvorslev yield surface and non-associated flow rule were adopted. No dilatancy was assumed 'dry of critical state' for the high-plasticity clay layers, which effectively blocked any progression towards critical states under either drained or undrained conditions, as is seen in laboratory shear tests. In the medium-plasticity clay layers, dilatancy was specified to reduce linearly from a maximum value at low stresses $\left(p^{\prime}=0\right)$ to zero at the critical-state point. A non-linear elastic-perfectly plastic Mohr-Coulomb model was adopted to characterise the behaviour of the sand layer. The elasticplastic soil models were combined with non-linear void ratio-permeability functions for the clay layers (Potts \& Zdravkovic, 1999).

A different model was applied for the plastic clay layers in analyses of potential progressive failure development following the last major landslide. In these stages, a nonlinear elastic strain-softening plastic Mohr-Coulomb model that accounted for any loss of shear strength (from peak towards residual) was adopted; Fig. 9 illustrates the brittleness function adopted. Ductile behaviour was modelled in the medium-plasticity clay or sand layers; their failure and yielding parameters remained unchanged from those adopted in the earlier 'geological modelling' stages, as did the nonlinear permeability functions for all strata. Parameter selec-

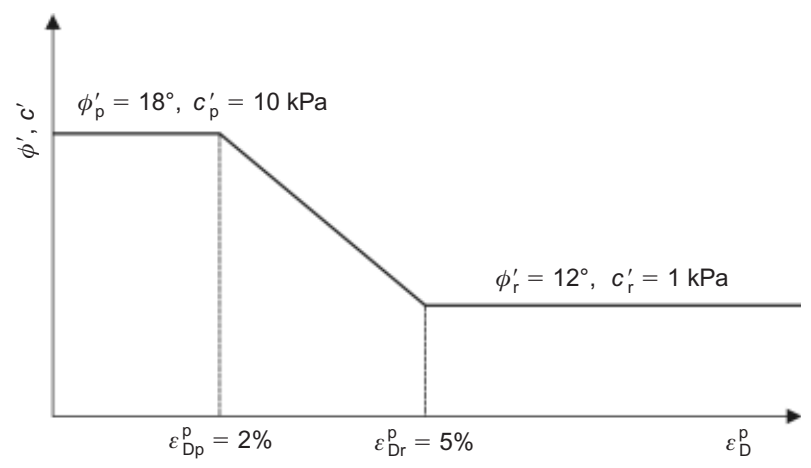

Fig. 9. Brittle shear characteristics of high-plasticity clay layers adopted for Mohr-Coulomb model in FE analyses of progressive failure since last major landslide $\left(\varepsilon_{\mathrm{D}}^{\mathrm{p}}\right.$ is deviatoric plastic strain invariant) 
tion was based, wherever possible, on data from tests on nearby deep boreholes. Tables 1 to 4 summarise the key input parameters. Two main clay types and one sand layer were considered, with an additional Holocene top clay layer.

In general, the main high- and medium-plasticity clay types were distinguished by the former having lower unit weights and higher compressibility. The changes in unit weight ascribed to various soil layers were not accounted for in the large-displacement analyses presented herein. The compressibility parameters were derived from oedometer test data that were adjusted to match the 'sedimentary' water content depth profiles shown by deep boreholes at sites away from the slope edge. To this extent they included the effects of the clay's natural structure, slow sedimentation and in situ ageing. The shear strength parameters, based on available direct simple shear (DSS), triaxial and ring-shear tests, were also less favourable for the plastic clay layers, especially under large-displacement 'residual conditions'. FE simulations were made to check the undrained shearing behaviour of the clay layers, considering $K_{0}$ consolidated samples tested in SHANSEP ideal DSS tests at overconsolidation ratios (OCRs) between 1 and 10. Comparisons with tests on deep borehole samples confirmed that the FE predictions were reasonable over this range. Similar checks were made for the permeability and non-linear stiffness relationships, and for the field void ratio-depth profiles.

Bishop ring-shear tests performed on six samples at Imperial College gave the results summarised in Table 5. The ring-shear tests reached stable residual shear strengths after post-slip displacements of $200-300 \mathrm{~mm}$. It can be seen that the two samples tested with $\mathrm{LL}<57 \%$ showed only modest reductions from an average peak $\varphi_{\mathrm{p}}^{\prime}=28^{\circ}$ towards an average $\varphi_{\mathrm{r}}^{\prime}=23 \cdot 5^{\circ}$. Taken together with triaxial and DSS data, an operational, non-softening, value of $25^{\circ}$ was selected. The four more plastic specimens were markedly brittle, with $\phi^{\prime}$ values falling from an average peak of $21.8^{\circ}$ to finally give $10 \cdot 5^{\circ}<\varphi_{\mathrm{r}}^{\prime}<14 \cdot 5^{\circ}$. Noting the lower peak angles developed in some triaxial and DSS tests that may have contained fissures, $18^{\circ}$ was adopted as the operational peak $\phi^{\prime}$ for the plastic layers. Considering ring-shear data from other sites in

Table 1. Soil properties adopted in FE analyses employing critical-state models for soils, covering 600000 BP up to c. $5000-8000$ BP

\begin{tabular}{|c|c|c|c|}
\hline \multirow[t]{2}{*}{ Property } & \multicolumn{3}{|c|}{ Value } \\
\hline & Medium-plasticity clay & High-plasticity clay & Top plastic clay layer \\
\hline $\begin{array}{l}\text { Bulk unit weight, } \gamma: \mathrm{kN} / \mathrm{m}^{3} \\
\text { Specific volume at unit pressure, } \nu_{1} \\
\text { Slope of virgin compression line, } \lambda \\
\text { Slopes of swelling lines, } \kappa \text { (nominal values }{ }^{*} \text { ) } \\
\text { Angle of shearing resistance, } \phi^{\prime} \text { ': degrees } \\
\text { Slope of Hvorslev surface with respect to slope of critical-state line } \\
\text { Angle of dilation on 'dry' side, } \psi: \text { degrees } \\
\text { Coefficient of earth pressure at rest, } K_{0} \text { (initial values) }\end{array}$ & $\begin{array}{c}17 \cdot 6 \\
3 \cdot 12 \\
0 \cdot 187 \\
0 \cdot 023 \\
25 \\
0 \cdot 5 \\
12 \cdot 5 \\
0 \cdot 60\end{array}$ & $\begin{array}{c}16 \cdot 2 \\
3 \cdot 75 \\
0 \cdot 250 \\
0 \cdot 031 \\
18 \\
0 \cdot 5 \\
0 \\
0 \cdot 65\end{array}$ & $\begin{array}{c}15 \cdot 3 \\
4 \cdot 50 \\
0 \cdot 330 \\
0 \cdot 041 \\
18 \\
1 \cdot 0 \\
0 \\
0 \cdot 70\end{array}$ \\
\hline Coefficient of permeability, $k: \mathrm{m} /$ year & \multicolumn{3}{|c|}{$\begin{array}{c}\ln k=a+b e, \text { where } e \text { is the void ratio } \\
\quad a=-9 \cdot 818, b=4 \cdot 413\end{array}$} \\
\hline
\end{tabular}

* Small-strain stiffness model used to characterise elastic response.

${ }^{\dagger}$ Angle of dilation changes linearly from $12 \cdot 5^{\circ}$ at $p^{\prime}=0$ to zero when critical state is reached.

Table 2. Mohr-Coulomb model parameters for progressive failure FE analyses over period following last major landslide (c. 50008000 BP)

\begin{tabular}{|c|c|c|c|c|c|c|c|c|c|}
\hline \multirow[t]{2}{*}{ Material } & \multirow{2}{*}{$\begin{array}{c}\text { Unit } \\
\text { weight, } \\
\gamma: \\
\mathrm{kN} / \mathrm{m}^{3}\end{array}$} & \multicolumn{2}{|c|}{$\begin{array}{c}\text { *Effective cohesion, } \\
c^{\prime}: \mathrm{kN} / \mathrm{m}^{2}\end{array}$} & \multicolumn{2}{|c|}{$\begin{array}{l}{ }^{*} \text { Effective angle of shearing } \\
\text { resistance, } \phi^{\prime}: \text { degrees }\end{array}$} & \multirow{2}{*}{$\begin{array}{l}\text { Angle of } \\
\text { dilation, } \psi \text { : } \\
\text { degrees }\end{array}$} & \multirow{2}{*}{$\begin{array}{c}\text { Coefficient of } \\
\text { earth pressure } \\
\text { at rest, } K_{0}\end{array}$} & \multirow{2}{*}{$\begin{array}{l}\text { Young's } \\
\text { modulus, } \\
E: \mathrm{kN} / \mathrm{m}^{2}\end{array}$} & \multirow[t]{2}{*}{$\begin{array}{l}\text { Poisson's } \\
\text { ratio, } \mu\end{array}$} \\
\hline & & Peak & Residual & Peak & Residual & & & & \\
\hline Sand layer & 20 & \multicolumn{2}{|r|}{0} & \multicolumn{2}{|c|}{30} & 0 & $0 \cdot 5$ & \multirow{2}{*}{\multicolumn{2}{|c|}{$\begin{array}{l}\text { Non-linear elastic small- } \\
\text { strain stiffness model used }\end{array}$}} \\
\hline $\begin{array}{l}\text { High-plasticity clay layers in } \\
\text { strain-softening analysis }\end{array}$ & $16 \cdot 2$ & 10 & 1 & 18 & 12 & 0 & 0.65 (initial) & & \\
\hline
\end{tabular}

${ }^{*}$ Strain-softening starts at $\varepsilon_{\mathrm{D}}^{\mathrm{p}}=2 \%$ (peak strength mobilised) and finishes at $\varepsilon_{\mathrm{D}}^{\mathrm{p}}=5 \%$ (residual strength reached), where $\varepsilon_{\mathrm{D}}^{\mathrm{p}}$ is the deviatoric plastic strain invariant (see Fig. 9).

Table 3. Coefficient and limits for non-linear elastic secant shear modulus $\left(G^{\text {sec }}\right)$ expression

\begin{tabular}{|c|c|c|c|c|c|c|c|c|}
\hline Stratum & $A$ & $B$ & $C: \%$ & $\alpha$ & $\gamma$ & $\varepsilon_{\mathrm{D}, \min }: \%$ & $\varepsilon_{\mathrm{D}, \max }: \%$ & $G_{\min }: \mathrm{kPa}$ \\
\hline $\begin{array}{l}\text { Medium-plasticity clay } \\
\text { High-plasticity clay } \\
\text { Top plastic clay layer } \\
\text { Sand layer }\end{array}$ & $\begin{array}{l}849 \cdot 5 \\
1000 \\
736 \cdot 8 \\
1869\end{array}$ & $\begin{array}{l}876 \cdot 8 \\
907 \cdot 1 \\
668 \cdot 4 \\
1929\end{array}$ & $\begin{array}{l}7 \times 10^{-4} \\
1 \times 10^{-4} \\
1 \times 10^{-4} \\
7 \times 10^{-4}\end{array}$ & $\begin{array}{l}1 \cdot 349 \\
1 \cdot 335 \\
1 \cdot 335 \\
1 \cdot 349\end{array}$ & $\begin{array}{l}0.6385 \\
0 \cdot 617 \\
0 \cdot 617 \\
0.6385\end{array}$ & $\begin{array}{l}5 \cdot 196 \times 10^{-3} \\
8 \cdot 66 \times 10^{-4} \\
8 \cdot 66 \times 10^{-4} \\
5 \cdot 196 \times 10^{-3}\end{array}$ & $\begin{array}{l}0 \cdot 26 \\
0 \cdot 693 \\
0 \cdot 693 \\
0 \cdot 26\end{array}$ & $\begin{array}{l}1000 \\
2666 \cdot 7 \\
2666 \cdot 7 \\
1000\end{array}$ \\
\hline
\end{tabular}

$3 G^{\mathrm{sec}} / p^{\prime}=A+B \cos \left[\alpha\left\{\log _{10}\left[\varepsilon_{\mathrm{D}} /(\sqrt{3} C)\right]\right\}^{\gamma}\right]$, where $\varepsilon_{\mathrm{D}}$ is the deviatoric strain invariant, defined as $\varepsilon_{\mathrm{D}}^{2}=\frac{2}{3}\left[\left(\varepsilon_{1}-\varepsilon_{2}\right)^{2}+\left(\varepsilon_{2}-\varepsilon_{3}\right)^{2}\right.$ $\left.+\left(\varepsilon_{3}-\varepsilon_{1}\right)^{2}\right]$. 
Table 4. Coefficient and limits for non-linear elastic secant bulk modulus $\left(K^{\text {sec }}\right)$ expression

\begin{tabular}{|c|c|c|c|c|c|c|c|c|}
\hline Stratum & $R$ & $S$ & $T: \%$ & $\delta$ & $\lambda$ & $\varepsilon_{\mathrm{v}, \min }: \%$ & $\varepsilon_{\mathrm{V}, \max }: \%$ & $K_{\min }: \mathrm{kPa}$ \\
\hline $\begin{array}{l}\text { Medium-plasticity clay } \\
\text { High-plasticity clay } \\
\text { Top plastic clay layer } \\
\text { Sand layer }\end{array}$ & $\begin{array}{l}266 \cdot 8 \\
490 \\
361 \\
587\end{array}$ & $\begin{array}{l}187 \cdot 3 \\
452 \cdot 1 \\
333 \cdot 1 \\
412\end{array}$ & $\begin{array}{l}7 \times 10^{-4} \\
1 \times 10^{-3} \\
1 \times 10^{-3} \\
7 \times 10^{-4}\end{array}$ & $\begin{array}{l}1 \cdot 4 \\
2 \cdot 069 \\
2 \cdot 069 \\
1 \cdot 4\end{array}$ & $\begin{array}{l}0 \cdot 797 \\
0 \cdot 42 \\
0 \cdot 42 \\
0 \cdot 797\end{array}$ & $\begin{array}{l}3 \times 10^{-3} \\
5 \times 10^{-3} \\
5 \times 10^{-3} \\
3 \times 10^{-3}\end{array}$ & $\begin{array}{l}0 \cdot 2 \\
0 \cdot 15 \\
0 \cdot 15 \\
0 \cdot 2\end{array}$ & $\begin{array}{l}2500 \\
5000 \\
5000 \\
2500\end{array}$ \\
\hline
\end{tabular}

$K^{\mathrm{sec}} / p^{\prime}=R+S \cos \left\{\delta\left[\log _{10}\left(\left|\varepsilon_{\mathrm{V}}\right| / T\right)\right]^{\lambda}\right\}$, where $\varepsilon_{\mathrm{v}}$ is the volumetric strain, defined as $\varepsilon_{\mathrm{v}}=\varepsilon_{1}+\varepsilon_{2}+\varepsilon_{3}$.

Table 5. Key results from ring-shear tests run with Bishop apparatus

\begin{tabular}{l|c|c|c}
\hline Liquid limit, LL: \% & Plasticity index, PI: \% & Peak angle of shearing resistance, $\varphi_{\mathrm{p}}^{\prime}$ : degrees & Ultimate angle of shearing resistance, $\varphi_{\mathrm{r}}^{\prime}$ : degrees \\
\hline $56 \cdot 9$ & $33 \cdot 3$ & 30 & 23 \\
$65 \cdot 1$ & $39 \cdot 5$ & 22 & $10 \cdot 5$ \\
$79 \cdot 6$ & $46 \cdot 3$ & 21 & 12 \\
$51 \cdot 7$ & $28 \cdot 1$ & 26 & 24 \\
$73 \cdot 9$ & $39 \cdot 8$ & $20 \cdot 5$ & $14 \cdot 5$ \\
$57 \cdot 5$ & $33 \cdot 2$ & $10 \cdot 5$ \\
\hline
\end{tabular}

the region, and noting the tendency for ring-shear ultimate values to provide lower bounds for landslides, the best estimate for $\varphi_{\mathrm{r}}^{\prime}$ was taken as $12^{\circ}$, although a check run was also undertaken with $\varphi_{\mathrm{r}}^{\prime}=13^{\circ}$. This softening was treated in the FE analyses in terms of 'smeared' equivalent plastic shear strain levels (Potts et al., 1990, 1997). To match the ring-shear slip displacements, a strain-softening law was specified (see Fig. 9) that accounted for the thickness of the typical finite elements chosen to represent the brittle highplasticity material. Plane-strain, eight-noded isoparametric elements with 'reduced' $2 \times 2$ integration were used in the FE analyses. The shear displacement required to reach residual strength was governed by the half thicknesses of the relevant finite elements. Considering a typical $10 \mathrm{~m}$ thick element, a plastic shear strain of $\varepsilon_{\operatorname{Dr}}^{p}=5 \%$ (see Fig. 9) was required to obtain the targeted local 'slip' of approximately $250 \mathrm{~mm}$. Parametric studies, performed as part of other investigations (e.g. Kovacevic, 1994), have shown that, when varied over a realistic range, the rate of strain-softening does not have a major influence on the results obtained.

The progressive failure analyses involved relatively small strains up to collapse, and their pre-yield behaviour was simulated by the non-linear, pressure-dependent stiffness expressions outlined by Jardine \& Potts (1988). The coefficients listed in Tables 3 and 4 were estimated by scaling results from tests by Jardine (1985) on other clays in proportion to the clay's compressibility parameters.

\section{KEY FINDINGS AND DISCUSSION}

The main aim was to assess current slope stability against potential progressive failure. Fig. 10 presents the key results from three analyses in terms of the horizontal movement expected at a mid-slope location (Point A in Fig. 8) plotted against time since the simulated landslide. In each case one or more residual shear surfaces developed progressively from the slope front upwards. Unstable runs manifested uncontrollable increases in the horizontal displacements as the shear surfaces propagated to complete full mechanisms, implying very high slide mass velocities, while the displacements seen in stable runs eventually halted, leaving partially formed mechanisms. Landslides might be able to exploit a preexisting discontinuity set, but this was not a necessary condition for instability.

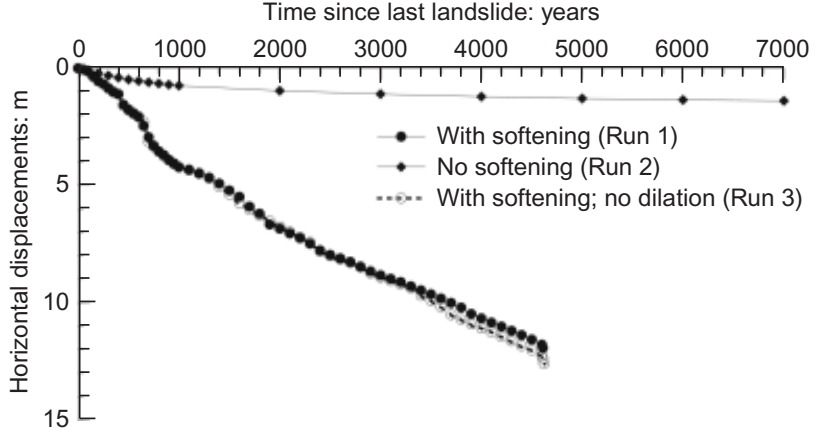

Fig. 10. Horizontal displacements predicted for Point A, as identified in Fig. 8, since last major landslide in analyses covering both brittle and non-brittle cases

The Run 1 calculations, which are based on first bestestimate parameters and assumptions, predict that swelling and residual fabric formation would reduce the margin of stability from around 1.24 (immediately after the last landslide c. 5000-8000 BP) to give marginally stable conditions after c. 2000 years and a sudden failure after c. 4750 years. Disabling the plastic clay's brittleness in Run 2 produced the entirely stable result illustrated in Fig. 10, where c. 7000 years were required to reach full hydraulic equilibrium. Removing dilation within the medium plastic clay layers (Run 3) had only a minor impact on stability and ground movements. A further check (Run 4) revealed a high sensitivity to the high-plasticity clay's ultimate residual $\varphi_{\mathrm{r}}^{\prime}$. A $1^{\circ}$ increase from $12^{\circ}$ to $13^{\circ}$ (an $8.6 \%$ increase in effective shear resistance) halted the progressive failure mechanism, and led to ground movements growing slowly over 12000 years until full equilibrium was attained. A further check analysis (Run 5) demonstrated that the presence of a single sand layer did not impact significantly on the overall stability trends.

The times to failure can be interpreted as being indicative of the recurrence periods for the cycles of instability associated with any particular set of soil parameters and modelling assumptions. Changing even the dilation or strainsoftening parameters influences the pore pressure change, volume change and hence permeability characteristics, and so affects the equalisation times. 
The key practical points to emerge are as follows.

(a) Delayed progressive failure mechanisms should be expected to be active under the escarpment slope.

(b) Stability deteriorates with time after the last landslide, until either a failure occurs or a stable minimum is reached when hydraulic equilibrium is restored.

(c) The expected equalisation times are predicted to fall between 7000 and 12000 years, and the age of the last landslide is interpreted as 5000-8000 BP.

(d) Best-estimate analyses indicate that instability is more probable than not over the remainder of the equalisation period, which may run for a further 2000-7000 years.

(e) The best estimate for the collapse time falls just short of the range interpreted for the time elapsed since the last landslide. However, this outcome has to be considered together with the sensitivity of the equalisation time calculations to the controlling soil parameters, and the potential uncertainty in the last landslide date assessment.

Overall, the best-estimate analysis suggests that renewed slope failure is likely over the next few thousand years. Inverting this assessment suggests reasonable values for the annual probability of failure. It should be recognised that any final instability might well be triggered by any new, unmodelled perturbation, such as new erosion or seismic activity.

The numerical analyses also provide valuable insights into the modes of potential failures. Fig. 11 illustrates the Run 1 failure mechanism and the plastic shear-straining pattern predicted just prior to failure, and Fig. 12 shows the current displacement vectors predicted just before collapse. Partially developed mechanisms are evident in each of the plastic clay layers, with the deepest two showing the most advanced progression. The analyses reveal that stability is not unduly sensitive to the precise system of layering. The main requirement for a delayed slope failure is the presence of continuous layers of brittle plastic clay draped over the diapir with residual $\varphi_{\mathrm{r}}^{\prime}$ angles falling towards, or below, the assessed $12^{\circ}$ value.

The Run 1 failure is predicted to develop horizontal movement rates of $20-30 \mathrm{~mm} /$ year over the decade preceding collapse (see Fig. 13), followed by very high post-failure

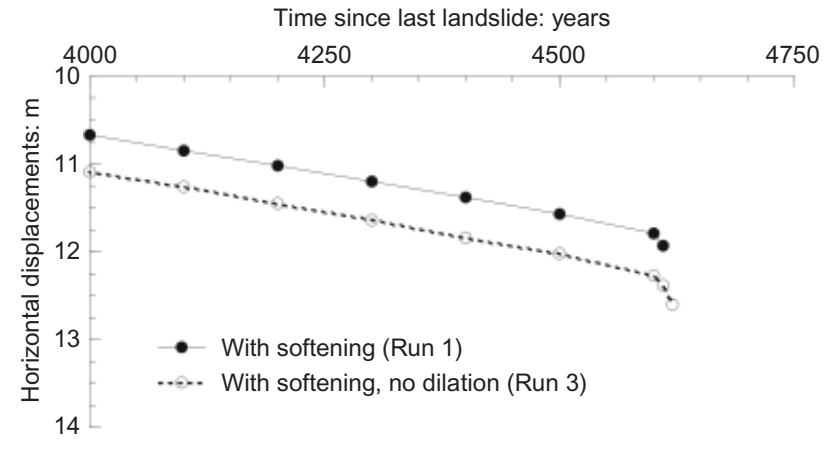

Fig. 13. Horizontal displacements predicted for Point $A$, as identified in Fig. 8, over final stages of progressive failure since last major landslide

velocities. However, the unmodelled but well-known tendency of clays to show accelerating creep rates as they approach any load-controlled failure would probably lead to velocities picking up to moderately higher rates before collapse. In the same way, positive shear-strength rate effects could be expected to apply once the progressive failure mechanism reached its final conclusion, which would act to limit the slide mass velocities once the collapse was fully under way.

\section{CONCLUSIONS}

Multiple, large relic underwater slope failures have been observed at deep water escarpment sites in the Gulf of Mexico. This paper has described a series of simulations aimed at understanding the escarpment's geological and geotechnical histories and so aiding geohazard assessment. The modelling considered how one section of escarpment evolved over the last 600000 years in response to local salt diapir uplift, sediment distortion and fresh deposition. A best-estimate analysis has been developed through a synthesis and interpretation of: (a) the available geological, geophysical and geotechnical data, including deep borings at neighbouring sites; and (b) new ring-shear tests on deep-

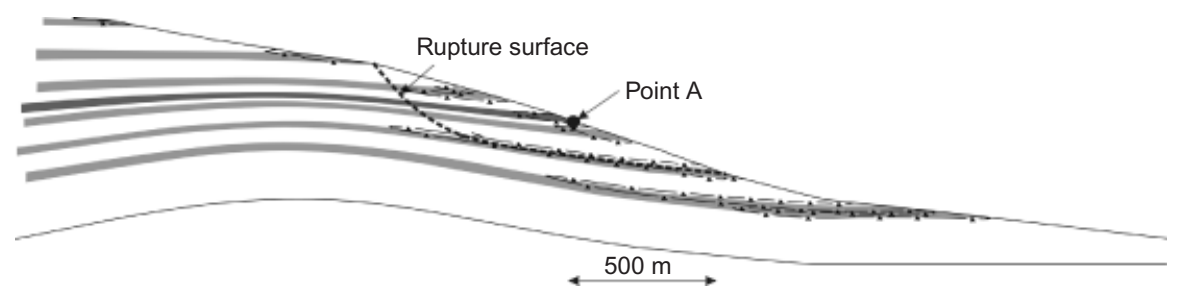

Fig. 11. Failure mechanism developed in best-estimate FE analysis of slope, considering progressive failure since last major landslide, revealing plastic strain concentrations in brittle clay layers as contours of deviatoric plastic strain invariant $\varepsilon_{D}^{p}=5 \%$. Note: no vertical exaggeration of scale

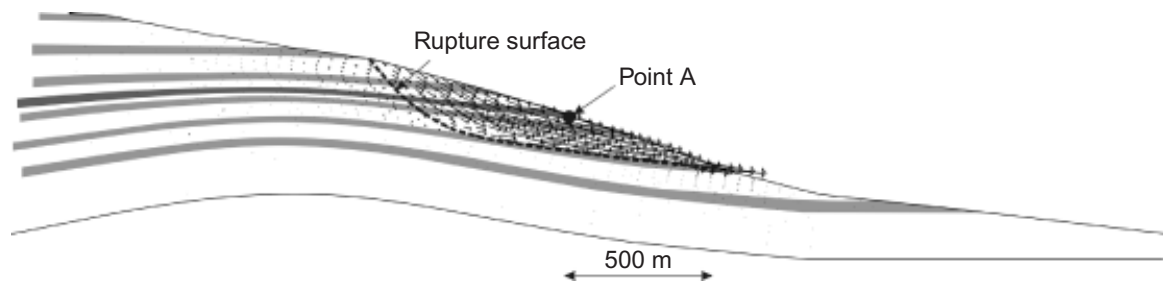

Fig. 12. Failure mechanism developed in best-estimate FE analysis of slope, considering pattern of predicted incremental displacements just prior to collapse. Note: no vertical exaggeration of scale 
water samples. The study underscores the importance of (a) acquiring high-quality geophysical and geotechnical data and (b) taking due account of uncertainties in the geological and geotechnical information.

The main conclusions are as follows.

(a) The acquisition of high-quality geophysical and geotechnical data is vital to any quantitative risk assessments regarding possible progressive slope failures. Highresolution $3 \mathrm{D}$ seismic geophysical data and detailed geotechnical testing were crucial in identifying and quantifying the structural evolution of the escarpment and its slope stability through to current times.

(b) It is possible to replicate the interpreted processes of simultaneous sedimentation and salt diapir uplift over a geologically significant timescale through advanced FE element analyses.

(c) It is also feasible to model delayed slope failures that may develop thousands of years after earlier instabilities that trigger cycles of pore pressure equalisation and progressive failure in brittle clay soils.

(d) The key requirement for a failure to develop is the presence of continuous layers of brittle clay layers with low $\varphi_{\mathrm{r}}^{\prime}$ distributed at various depths within the sediment stack. Failure could also develop by exploiting an existing (not modelled) optimally positioned, existing discontinuity set. However, this is not a necessary condition for instability.

(e) Numerical analyses allow recurrence periods to be estimated for the next potential large-scale escarpment slope instability from the interpreted geological history and geotechnical characteristics, including the brittleness of the clays present.

( $f$ ) The best-estimate analysis indicates a delayed failure mechanism involving a large mass that can be expected to slide midway through the period required for full hydraulic equalisation after the last major instability.

(g) Stability conditions at the study location are likely to have been marginal for at least 2000 years, and failure may be expected within the next few thousand years.

(h) The study helps to identify reasonable estimates for the current annual probability of slope failure. Geohazard assessments in which the likelihood of future events is based on dating past events without addressing probable slumping recurrence intervals may give misleading results.

(i) The numerical analyses suggest that only modest rates of displacement may develop before a sudden brittle failure occurs. The low velocities predicted immediately prior to collapse could be detected only with special instrumentation. However, it is recognised that unmodelled creep effects may lead to higher-than-predicted velocities in the run-up to any real field failure. Equally, unmodelled positive rate effects could provide temporarily raised shear strengths that could reduce slide mass velocities during the final collapse.

\section{ACKNOWLEDGEMENTS}

The authors acknowledge gratefully BP America's support for the work described, and for their permission to publish. They also acknowledge the work of Dr N. Anh Minh in performing the ring-shear tests at Imperial College.

\section{NOTATION}

$\begin{array}{ll}c^{\prime} & \text { effective cohesion } \\ c_{\mathrm{p}}^{\prime} & \text { peak cohesion }\end{array}$

$c_{\mathrm{r}}^{\prime}$ residual cohesion
$E$ Young's modulus

$e$ void ratio

$G_{\min }$ minimum shear modulus

$G^{\text {sec }}$ non-linear elastic secant shear modulus

$K_{\min } \quad$ minimum bulk modulus

$K^{\mathrm{sec}}$ non-linear elastic secant bulk modulus

$K_{0}$ coefficient of earth pressure at rest

$k$ coefficient of permeability

$p^{\prime}$ mean effective stress

$v_{1}$ specific volume at unit pressure

$\gamma$ bulk unit weight

$\varepsilon_{\mathrm{D}}$ deviatoric strain invariant

$\varepsilon_{\mathrm{D}, \max }$ maximum deviatoric strain invariant

$\varepsilon_{\mathrm{D}, \text { min }}$ minimum deviatoric strain invariant

$\varepsilon_{\mathrm{D}}^{\mathrm{p}}$ deviatoric plastic strain invariant

$\varepsilon_{\mathrm{Dp}}^{\mathrm{p}} \quad$ deviatoric plastic strain invariant at peak

$\varepsilon_{\mathrm{Dr}}^{\mathrm{p}} \quad$ deviatoric plastic strain invariant at residual

$\varepsilon_{\mathrm{v}} \quad$ volumetric strain

$\varepsilon_{\mathrm{v}, \max }$ maximum volumetric strain

$\varepsilon_{\mathrm{v}, \text { min }}$ minimum volumetric strain

$\varepsilon_{1}, \varepsilon_{2}, \varepsilon_{3}$ principal strains

$\kappa$ slope of swelling lines

$\lambda$ slope of virgin compression line

$\mu$ Poisson's ratio

$\phi^{\prime}$ effective angle of shearing resistance

$\varphi_{\mathrm{p}}^{\prime}$ peak angle of shearing resistance

$\varphi_{\mathrm{r}}^{\prime}$ residual angle of shearing resistance

$\psi$ angle of dilation

\section{REFERENCES}

Chandler, R. J., Willis, M. R., Hamilton, P. S. \& Andreau, I. (1998). Tectonic shear zones in the London Clay Formation. Géotechnique 48, No. 2, 257-270, http://dx.doi.org/10.1680/ geot.1998.48.2.257.

Cloos, E. (1968). Experimental analysis of Gulf Coast fracture patterns. AAPG Bull. 52, No. 3, 420-444.

Gens, A. \& Potts, D. M. (1988). Critical state models in computational geomechanics. Engng Comput. 1, No. 2, 144-150.

Hutchinson, J. N. (1973). The response of London Clay cliffs to differing rates of toe erosion. Geol. Appl. Idrogeol. 7, Part 1, $222-239$

Jardine, R. J. (1985). Investigations of pile-soil behaviour, with special reference to the foundations of offshore structures. $\mathrm{PhD}$ thesis, Imperial College, University of London, UK.

Jardine, R. J. \& Potts, D. M. (1988). Hutton tension leg platform foundations: predictions of driven pile behaviour. Géotechnique 38, No. 2, 231-252, http://dx.doi.org/10.1680/geot.1988.38.2. 231.

Kovacevic, N. (1994). Numerical analyses of rockfill dams, cut slopes and road embankments. $\mathrm{PhD}$ thesis, Imperial College, University of London, UK.

Kovacevic, N., Hight, D. W. \& Potts, D. P. (2007). Predicting the stand up time of temporary London Clay slopes at Terminal 5, Heathrow Airport. Géotechnique 57, No. 1, 63-74, http:// dx.doi.org/10.1680/geot.2007.57.1.63.

Kvalstad, T. J., Nadim, F., Kaynia, A. M., Mokkelbost, K. H. \& Bryn, H. P. (2005). Soil conditions and slope stability in the Ormen Lange area. Mar. Petrol. Geol. 22, No. 1-2, 299-310.

Nowacki, F., Solhjell, E., Nadim, F., Liedke, E., Andersen, K. H. \& Andresen, L. (2003). Deterministic slope stability analyses of the Sigsbee Escarpment. Proc. Offshore Technol. Conf., Houston, $T X$, paper OTC 15160 .

Orange, D. L., Angell, M. M., Brand, J. R., Thomson, J., Buddin, M. W., Hard, W. \& Berger, W. J. (2003). Geological and shallow tectonic setting of the Mad Dog and Atlantis fields: relationships between salt, faults and seafloor geomorphology. Proc. Offshore Technol. Conf., Houston, TX, paper OTC 15157.

Parsons, A. W. \& Perry, J. (1985). Slope stability problems in ageing highway networks. Proceedings of the ICE symposium on failure on earthworks, pp. 63-79. London, UK: Thomas Telford.

Potts, D. M. \& Zdravkovic, L. (1999). Finite element analysis in geotechnical engineering: Theory. London, UK: Thomas Telford.

Potts, D. M. \& Zdravkovic, L. (2000). Finite element analysis in 
geotechnical engineering: Applications. London, UK: Thomas Telford.

Potts, D. M., Dounias, G. T. \& Vaughan, P. R. (1990). Finite element analysis of progressive failure of Carsington embankment. Géotechnique 40, No. 1, 79-101, http://dx.doi.org/10. 1680/geot.1990.40.1.79.

Potts, D. M., Kovacevic, N. \& Vaughan, P. R. (1997). Delayed collapse of cut slopes in stiff clay. Géotechnique 47, No. 5, 953-982, http://dx.doi.org/10.1680/geot.1997.47.5.953.

Poulos, H. G. (1988). Marine geotechnics. Boston, MA, USA: Unwin Hyman.
Roscoe, K. H. \& Burland, J. B. (1968). On the generalised stressstrain behaviour of 'wet' clay. In Engineering plasticity (eds J. Heyman and F. A. Leckie), pp. 535-609. Cambridge, UK: Cambridge University Press.

Skempton, A. W. (1977). Slope stability of cuttings in brown London Clay. Proc. 9th Int. Conf. Soil Mech. Found. Engng, Tokyo 3, 261-270.

Young, A. G., Bryant, W. R., Slowey, N. C., Brand, J. R. \& Garter, S. (2003). The dating of past slope failures of the Sigsbee escarpment within Atlantis and Mad Dog developments. Proc. Offshore Technol. Conf., Houston, TX, paper OTC 15204. 